\title{
Tales de Mileto e a medição da altura da pirâmide*
}

\section{Thales of Miletus and the measurement of the height of the pyramid}

\author{
Júlio Fontanał
}

\begin{abstract}
Resumo
Qualquer pessoa que tenha frequentado a escola até o Ensino Médio certamente conhece a história da medição da altura da pirâmide realizada por Tales de Mileto no século VI a.C. Conta-se que ele fez isso utilizando um teorema geométrico que, posteriormente, ficou conhecido pelo seu nome: o teorema de Tales. No entanto, lamentavelmente, muitos livros e enciclopédias repetem histórias que não possuem nenhum fundamento. Examinar-se-á o caso do relato de medição da pirâmide atribuída a Tales a fim de constatar se ele consiste num desses casos.

Palavras-chave: história da ciência - história da matemática - geometria - Tales de Mileto
\end{abstract}

\begin{abstract}
Anybody who has attended secondary school surely knows the history of the measurement of the height of the pyramid that was accomplished by Thales of Miletus in the sixth century BC. It is reported that he achieved it by using a geometrical theorem that, later, was known by his name: Thales' theorem. Regrettably, however, many books and encyclopedias repeat stories that are without foundation. The report of how Thales measured the height of the pyramid will be examined in order to determine whether it is one of these stories.

Keywords: history of science - history of mathematics - geometry - Thales of Miletus
\end{abstract}

\footnotetext{
* Recibido: 17 Marzo 2011. Aceptado en versión revisada: 10 Julio 2011.

† Programa de Pós-Graduação Lógica e Metafísica da Universidade Federal do Rio de Janeiro (PPGLM/ UFRJ) e Centro de Epistemologia e História da Ciência (CEPISHC). Para contatar o autor, por favor escreva a: juliocesarfontana@yahoo.com.br.

Metatheoria 2(1) (2011): 23-36. ISSN 1853-2322.

(C) Editorial de la Universidad Nacional de Tres de Febrero. Publicado en la República Argentina.
} 


\section{Introdução}

Qualquer pessoa que tenha frequentado a escola até o Ensino Médio certamente conhece a história da medição da altura da pirâmide realizada por Tales de Mileto no século VI a.C. Conta-se que ele fez isso utilizando um teorema que posteriormente ficou conhecido pelo seu nome: "o teorema de Tales". ${ }^{1}$

Contudo, como lamentou o físico e historiador da ciência Roberto de Andrade Martins, "muitos livros e enciclopédias repetem histórias que não possuem nenhum fundamento" (de Andrade Martins 2000, p. 115). Acredito que o relato da medição da pirâmide realizado por Tales consista em mais um destes casos. Os motivos que me levam a duvidar do relato tradicional são os seguintes:

1.1. a história pode ter sido fruto da criação de autores helenistas;

1.2. existem divergências entre os relatos que nos servem de fontes dessa história; e

1.3. exige-se condições muito propícias a fim de se efetuar a referida medição utilizando os conhecimentos matemáticos da época.

Irei examinar todos esses motivos esperando não só conceder uma resposta ao leitor quanto à historicidade do relato da medição da altura da pirâmide atribuída a Tales de Mileto, como, também, mostrar que o exame que será realizado neste artigo possui implicações importantes tanto para a história como para a filosofia da ciência.

\section{A história é fruto da criação de autores helenistas}

Ainda hoje, são sugeridas teorias que imputam a paternidade de muitas das realizações gregas aos orientais. ${ }^{2}$ Isso se deve a diversos motivos. ${ }^{3}$

O principal motivo, ao meu ver, é que a maior parte de nossas fontes referentes aos primórdios da filosofia ${ }^{4}$ estão inseridas no contexto do helenismo, e, por isso, narram a história da maneira como viam as coisas acontecerem em sua época. Neste momento da história, havia um grande intercâmbio cultural entre todas as civilizações que formavam o mundo helenístico. ${ }^{5}$ Por isso, ao descreverem o passado, eles projetavam seu mundo sobre aquele dos jônios, resultando

\footnotetext{
${ }^{1}$ Existem diversas versões do teorema de Tales, mas todas elas tratam basicamente de retas paralelas, que ora formam figuras, ora se estendem no espaço infinito. Vicenzo Bongiovanni compara as várias versões do teorema de Tales em Bongiovanni (2007, pp. 99-101).

${ }^{2}$ Remeto aqueles que almejam conhecer mais argumentos contra a derivação da filosofia do Oriente à exposição de Giovanni Reale em "Inconsistência da tese de uma presumível derivação da filosofia do Oriente", no primeiro volume de sua História da filosofia antiga. A exposição de Reale é muito mais completa do que a minha (Reale 1975-1980, pp. 12-18).

${ }^{3}$ Irei analisar somente a influência das fontes sobre os historiadores. Existem outros fatores, inclusive alguns externos à pesquisa histórica, como o orientalismo que, sob a influência do romantismo, erigiu o Oriente como o continente exemplar onde se originara todo o pensamento (Brun 1968, p. 11, Reale 1975-1980, p. 12).

${ }^{4}$ Os gregos não faziam distinção entre filosofia e ciência como hoje o fazemos. Pode-se constatar isso pelo relato de Écio $(\mathrm{I}, 3,1)$ no qual ele afirma que Tales se dedicou ao estudo da filosofia no Egito. O que ele possivelmente tentava expressar era que Tales aprendeu matemática no Egito, informação essa que foi fornecida por diversas fontes.

${ }^{5}$ Fora isso, existiu no Helenismo e no Renascimento "a crença de que o Egito era o sítio de origem de todo conhecimento, de que os filósofos gregos o haviam visitado e conversado com os sacerdotes do país” (Yates 1964, p. 17).
} 
na grande quantidade de relatos de empréstimos culturais entre as civilizações que vislumbramos em seus textos. ${ }^{6}$

Contudo, um intercâmbio cultural, principalmente filosófico, que envolve a apreensão de conceitos abstratos, era impossível na época dos pré-socráticos. Como afirma Burnet:

[...] a filosofia só se pode expressar em linguagem abstrata e só pode ser transmitida por homens instruídos, seja por meio de livros, seja de ensinamentos orais. Ora, não temos conhecimento de nenhum grego, na época sobre a qual estamos discorrendo, que fosse capaz de ler um livro egípcio ou mesmo de ouvir o discurso de um sacerdote egípcio [...]. É claro que um viajante grego no Egito assimilaria algumas palavras do egípcio, e é presumível que os sacerdotes conseguissem fazer-se entender pelos gregos. Mas eles deviam servir-se de intérpretes, e é impossível conceder que ideias filosóficas fossem comunicadas por meio de um dragomano sem instrução. (Burnet 1892, p. 32; confira também Havelock 1981, pp. 83s.)

Um outro fator que propiciou a atividade de criação destas histórias foi a disputa entre os sacerdotes egípcios e entre os judeus alexandrinos pela paternidade das fontes da filosofia em seu próprio passado. Nestas histórias contemplamos afirmações claras no sentido de que a filosofia teria vindo da Fenícia ou do Egito. Esta busca deu resultados muito criativos. Por meio de um processo de transformação dos mitos primitivos em alegorias tornou-se possível derivar toda a filosofia dos referidos mitos. ${ }^{7}$ Este método de interpretação foi aplicado pelos neopitagóricos e pelos neoplatonistas, que o transmitiram para os apologistas cristãos. Estes -neopitagóricos, neoplatônicos e os apologistas cristãos- constituem as nossas principais fontes da história da filosofia. ${ }^{8}$

Porém, nenhum autor do período em que floresceu a filosofia tinha qualquer conhecimento de que ela tivesse vindo do Oriente. Vejamos:

- Heródoto não deixaria de dizê-lo, se o tivesse ouvido, pois isso teria confirmado sua própria crença na origem egípcia da religião e da civilização gregas. ${ }^{9}$

-Platão, que tinha grande respeito pelos egípcios por outros motivos, classificou-os mais como um povo de negociantes do que de filósofos.

-Aristóteles fala apenas da origem da matemática no Egito.

Diante disso, afirma Burnet:

É importante reconhecer a verdadeira origem desse preconceito contra a originalidade dos gregos. Não provém das pesquisas modernas sobre as crenças

${ }^{6}$ Diôgenes de Laêrtios foi o primeiro a apontar para o absurdo de derivar a filosofia do Oriente. Ele disse: "Segundo alguns autores o estudo da filosofia começou entre os bárbaros. [...] Esses autores ignoram que os feitos por eles atribuídos aos bárbaros pertencem aos helenos, com os quais não somente a filosofia, mas a própria raça humana começou. [...] Assim começou a filosofia com os helenos, e seu próprio nome nada tem a ver com a maneira bárbara de expressar-se" (Laêrtios 2008, pp. 13s.).

${ }^{7}$ Um bom exemplo da utilização da alegoria para derivar a filosofia da Torah pode ser contemplado nos trabalhos hermenêuticos de Fílon de Alexandria.

${ }^{8}$ Os principais alvos dessas interpretações alegóricas foram Tales e Pitágoras.

${ }^{9}$ Jean Brun faz uma crítica a Heródoto quanto a essa aproximação. Ele diz: "Ora, Heródoto não sabe ler as inscrições nem os papiros e fia-se na tradição popular, sem se pôr o problema das fontes" (Brun 1968, p. 10). 
dos povos antigos, pois estas nada revelaram em matéria de evidências de uma filosofia fenícia ou egípcia. Trata-se de um mero resíduo da paixão alexandrina pela alegoria. (Burnet 1892, p. 31)

Não tenho qualquer dúvida de que os historiadores possuem consciência de tudo isso que falei aqui. Se eles ainda insistem em imputar paternidades orientais às realizações gregas é porque não conseguem admitir o caráter altamente criativo e original dos jônios do século VI a.C. e contra aqueles que o fazem eles dirigem a acusação de defender a doutrina do "milagre grego". ${ }^{10}$ Assim fizerem com John Burnet, o qual, na minha opinião, está muito longe de considerar qualquer realização dos jônios como um "milagre". ${ }^{11}$ Ele, pelo contrário, sustenta que:

o mar Egeu tinha sido o centro de uma civilização desenvolvida desde a era neolítica -uma civilização tão antiga quanto a do Egito ou a da Babilônia, e superior a ambas na maioria das coisas que contam. A cada dia fica mais claro que a civilização grega de épocas posteriores foi sobretudo uma revivescência e continuação dessa, embora sem dúvida tenha recebido alguns elementos novos importantes dos povos menos civilizados do norte, que suspenderam seu desenvolvimento por algum tempo. (Burnet 1892, p. 21; confira também Brun 1968, p. 10)

A pesquisa histórica de hoje mostra que a civilização egeia foi tão antiga quanto a egípcia e a babilônica e, por isso, afirma Burnet, com o qual concordo inteiramente, que "muito do que se considerou oriental pode muito bem ter sido nativo" (Burnet 1892, p. 30).

\section{As divergências entre os relatos que nos servem como fonte dessa história}

Estão disponíveis diversos relatos que descrevem a medição da altura da pirâmide feita por Tales de Mileto. A primeira e mais antiga é a citada por Diôgenes de Laêrtios (século II-III d.C.): "Hierônimos conta-nos que Tales mediu a altura das pirâmides pela sombra das mesmas, fazendo a medição na hora em que a nossa própria sombra corresponde ao nosso tamanho" (Laêrtios 2008, p. 19).

Hierônimos de Rodes atribui a Tales, supostamente, o método mais simples para medir a altura de uma pirâmide. ${ }^{12}$

Uma outra versão para a história foi fornecida por Plutarco (século I-II d.C).

Colocando a prumo uma vara no final da sombra da pirâmide e fazendo dois triângulos com a linha que traça o raio do sol quando toca as duas extremidades, ele mostrou que havia uma certa proporção entre a altura da pirâmide e a

\footnotetext{
${ }^{10}$ A doutrina do milagre grego é aquela que afirma enfaticamente que as realizações alcançadas pelos gregos se devem a sua peculiaridade diante dos outros povos, como os egípcios e os babilônios. Porém, afirmar que todas as realizações gregas foram tomadas de empréstimo desses povos é outra doutrina tão dogmática quanto aquela, a qual poderíamos batizar de "doutrina do plágio grego".

${ }^{11}$ Jean-Pierre Vernant foi o mais importante estudioso a acusar John Burnet de ser um defensor da doutrina do milagre grego (Vernant 1962, p. 111). Muitos, após ele, somente repetiram tal acusação, sem realizar qualquer exame da questão.

${ }^{12}$ Plínio apresenta uma variante desse relato (DK 11 A 21).
} 
des, ele mostrou que havia uma certa proporção entre a altura da pirâmide e a da vara correspondente ao comprimento da sombra de um à sombra de outro (DK 11 A 21).

Destes dois relatos, devemos dar preferência a primeira versão por ser mais intuitiva, muito mais concordante com o suposto conhecimento de um jônio do século VI a.C. A segunda versão, além de envolver o conceito de triângulo, atribui um conhecimento mais complexo a Tales, a saber, que a altura da pirâmide está para o comprimento da sua sombra, exatamente como a altura de qualquer objeto vertical mensurável está para o comprimento da sua sombra no mesmo momento do dia. ${ }^{13}$

O primeiro relato nos mostra que Tales estaria utilizando um conhecimento teórico rudimentar, a saber,

1. que a relação entre as sombras de dois objetos é a mesma num mesmo momento do dia.

Esse conhecimento teórico rudimentar é derivado de um outro, aquele que diz que

2. o Sol trata de modo igual as coisas.

Estes conhecimentos teóricos rudimentares -pertencentes ao campo da pesquisa astronômica- estavam acessíveis a Tales, principalmente pelo fato dele, segundo a maior parte de nossas fontes, ter demonstrado um particular interesse por questões ligadas ao comportamento dos céus. Acredito ainda que Tales tenha inferido daí que os raios do Sol são paralelos.

Vejamos um outro relato de medição supostamente efetuado por Tales: a medição da distância dos navios no alto mar. ${ }^{14}$ Este relato foi citado por Proclo (século VI d.C.): "Eudemo, na História da Geometria, atribui este teorema a Tales; é que o método segundo o qual se diz que ele demonstrou a distância dos navios no alto mar deve ter implicado, segundo o referido autor, o emprego deste teorema" (Kirk, Raven \& Schofield 1983, p. 80).

Poucos estudiosos se debruçaram sobre esses relatos de maneira crítica. Alguns, entretanto, tentaram dar explicações a fim de conciliar ou justificar os diversos relatos.

John Burnet explicou-os da seguinte forma: "Tanto a medição da distância dos navios no mar quanto a da altura das pirâmides, que também lhe é atribuída, são aplicações simples da regra fornecida por Ahmés para descobrir o seqt" (Burnet 1892, p. 62).

\footnotetext{
${ }^{13}$ Kirk acha que devemos optar pela segunda versão do relato de medição em virtude desse concordar com o relato feito por Proclo. Embora defenda que Tales aplicava o procedimento mais complexo, ele afirma que este cálculo podia ter sido feito com a ajuda de instrumentos de medição (Kirk, Raven \& Schofield 2008, p. 83).

${ }^{14} \mathrm{O}$ relato de Proclo sobre a medição da distância dos navios no mar é muito mais provável de ser histórico do que aquele referente à medição da altura da pirâmide, pois esse relato não só se dá no ambiente grego como também sabemos que Tales demonstrou profundo interesse pela ciência náutica. T.L. Heath conjecturou que essa medição deve ter sido feita com a utilização de um instrumento (um quadrante ou, talvez, duas barras articuladas). Tales apontava uma das hastes da barra para o navio, depois rodava a barra sobre o seu próprio eixo pedindo para alguém marcar no chão o ponto para o qual a haste agora apontava, efetuando por fim essa medição estava determinada a distância almejada (Eves 1958, p. 115; confira também Bongiovanni 2007, p. 97).
} 
O seqt é uma ferramenta de cálculo importante para a matemática egípcia. O papiro de Rhind (c. 1700 a.C.) menciona por quatro vezes o seqt de um ângulo, em conexão com alguns problemas métricos sobre pirâmides. $\mathrm{O}$ seqt do ângulo $\angle \mathrm{OMV}$ na figura abaixo é a razão entre $\mathrm{OM}$ e $\mathrm{OV}$ e, portanto, corresponde à ideia atual de cotangente.

\section{Figura 1}

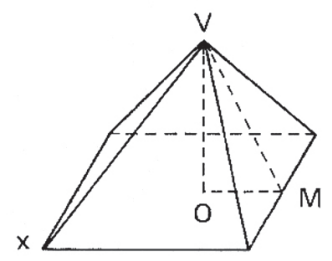

As pirâmides egípcias eram construídas de maneira a que a inclinação de uma face sobre a base (medida de $\angle \mathrm{OMV}$ ) fosse constante -aproximadamente $52^{\circ}-$.

Tales poderia ter aprendido a utilização do seqt com os egípcios, pois esse é um conhecimento técnico, na minha opinião transferível, todavia, de posse do seqt do ângulo formado pelo lado da base da pirâmide e sua respectiva face, Tales poderia, por exemplo, medir a altura da pirâmide sem recorrer a qualquer sombra. Isso, no entanto, não é o que foi relatado pelas fontes.

A explicação de G.S. Kirk parece mais plausível. Ele afirma que a medição da distância dos navios é possível da seguinte forma: "Uma vez que se conhecesse a altura do observador acima do nível do mar, este cálculo podia ter feito com a ajuda de um teodolito primitivo, duas varas (uma como linha de mira, a outra como linha de água aproximada), com um prego por eixo" (Kirk, Raven \& Schofield 1983, p. 83).

Daí, conclui que: "A minha própria hipótese é que Tales granjeou reputação entre os seus contemporâneos por ter realizado várias proezas de medição, que estavam longe de ser puramente empíricas, sem necessariamente determinar os princípios de geometria que lhes eram subjacentes" (Kirk, Raven \& Schofield 1983, p. 83).

Essa explicação é a melhor por dois motivos:

3.1. não retira Tales do seu contexto, isto é, o conhecimento que ele supostamente possuía não era tão distante assim do conhecimento matemático dos egípcios e dos babilônios. Portanto, desmistifica Tales.

3.2. ela explica por quê os sucessores diretos de Tales, Anaximandro e Anaxímenes, não desenvolveram a teoria matemática que seu mestre supostamente teria estabelecido as bases.

\section{Impossibilidade matemática da medição}

Até o momento examinei somente questões históricas atreladas ao relato de medição da pirâmide supostamente efetuada por Tales. Há, contudo, um outro argumento, só que agora de natureza matemática (e astronômica). 
A fraqueza matemática dos relatos de medição atribuídos a Tales, por incrível que pareça, não são enfatizados pelos historiadores da matemática. ${ }^{15}$

Segundo o relato de Plutarco, a partir de uma estaca colocada verticalmente e tomada à medida de sua sombra, tendo sido medido o comprimento da sombra que a pirâmide reflete no solo, é possível calcular a altura da pirâmide. Porém, essa medição não é obtida assim tão facilmente. Como observa Guedj, "se fosse um corpo delgado, a realização de Tales teria sido mais simples, a medição que ele acabava de efetuar teria bastado. Mas a pirâmide é mais larga embaixo" (Guedj 1998, p. 48).

A figura $2^{16}$ mostra como Tales pode ter imaginado as linhas geométricas que permitiriam o cálculo da altura da pirâmide.

\section{Figura 2}
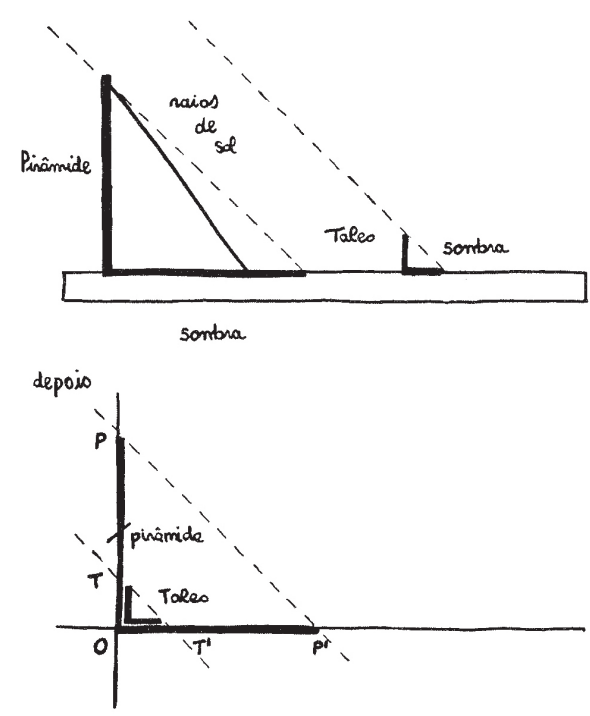

A situação real, portanto, que deveria ocorrer a fim de possibilitar o tipo de solução imaginada por Tales, é a mostrada pela figura 3.

Figura 3

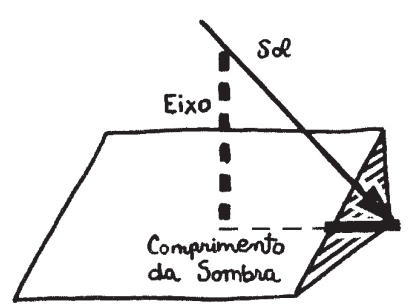

\footnotetext{
${ }^{15}$ Howard Eves aponta para a fraqueza do relato de medição da altura da pirâmide por Tales no Exercício 3.1., mas ele não o examina sob o aspecto da historicidade (Eves 1954, p. 115). Carl B. Boyer nem ao menos toca no assunto (Boyer 1968, pp. 30-33). O matemático Denis Guedj examinou essa fraqueza no seu livro O Teorema do Papagaio.

${ }^{16}$ As figuras foram retiradas do livro de Denis Guedj indicado na bibliografia.
} 
Sabemos que a base da pirâmide é quadrada e sua altura cai exatamente no meio dela. Portanto, a distância da altura ao lado da base é metade desse lado. Destarte, era preciso somente Tales medir a um dos lados da base da pirâmide e dividir por 2 para obter o tamanho da parte inacessível (figura 4).

Figura 4
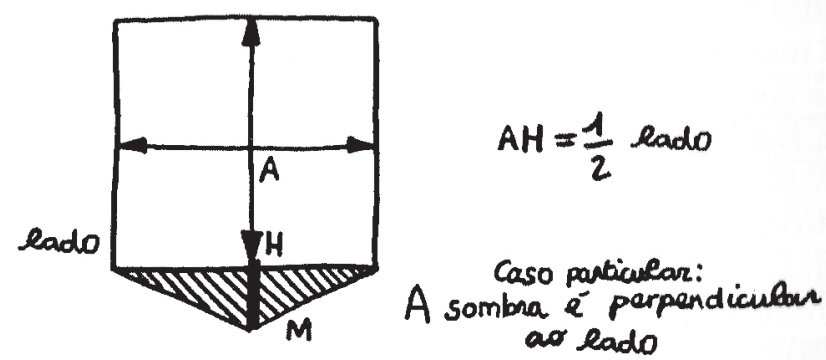$$
A H=\frac{1}{2} \text { lado }
$$

Caso particular:

A sombra é perpandiculour

ao eado

Porém, o caso mostrado nas figuras anteriores é uma interpretação ideal sobre o fenômeno, quando a sombra é perpendicular ao lado da base. São raras as vezes em que, durante o ano, isto acontece de forma tão exata. Ou seja, a sombra da pirâmide pode não estar exatamente na posição que permita a realização dos cálculos, como mostra a figura 5, ou então ocorre o caso de o Sol se posicionar de tal forma que não projeta qualquer sombra, como mostra a figura 6 .

Figura 5

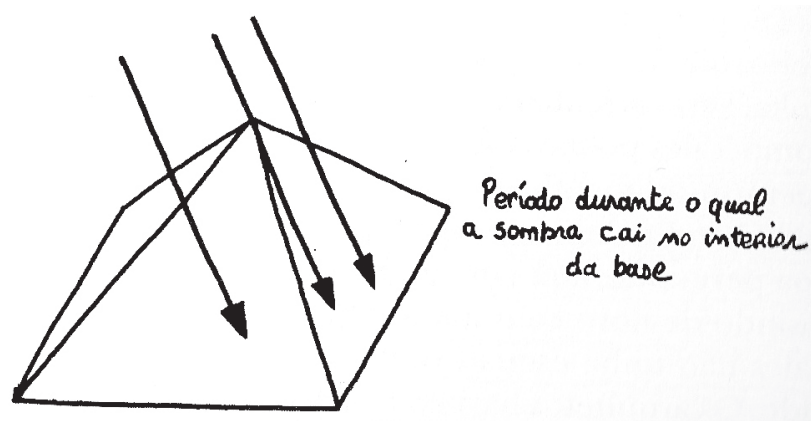

Figura 6

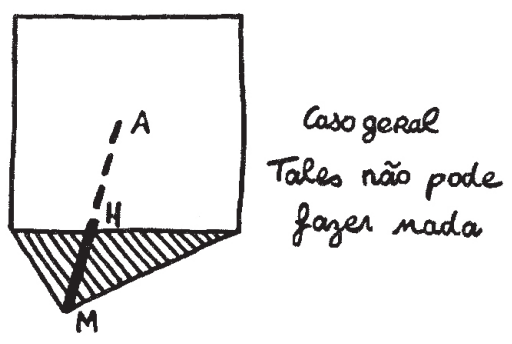


Destarte, para Tales proceder à medição da altura da pirâmide deve-se conjugar duas condições:

1. a sombra aparente da pirâmide mais $1 / 2$ do lado da base deve ser igual à altura da pirâmide, e

2. a sombra deve ser perpendicular à base.

Quando ocorre o fato da sombra aparente da pirâmide mais 1/2 do lado da base ser igual ao seu tamanho e perpendicular ao lado de sua base?

Para que a sombra seja igual ao objeto, os raios têm de estar inclinados a $45^{\circ} .{ }^{17} \mathrm{E}$ para que ela seja perpendicular à base, tem de estar orientada norte-sul. Segundo Guedj, essas condições só estão reunidas em dois dias por ano: 21 de novembro ou 20 de janeiro (Guedj 1998, p. 54). Em suma, são raros os períodos do ano em que o Sol se encontra em posição de oferecer uma sombra privilegiada para que se possa fazer as medições para se determinar, de forma um pouco mais precisa, a altura da pirâmide. Tales teria que ter passado o ano inteiro observando a pirâmide a fim de realizar tal tarefa, o que é muito improvável que tenha feito.

\section{Conclusão}

A partir do exame realizado aqui, verificamos que o relato que descreve Tales medindo a altura de uma pirâmide no Egito foi criado posteriormente. Não somente apontamos problemas históricos, como também fraquezas matemáticas, envolvendo os relatos que sustentam a famosa anedota. Esse é mais um daqueles casos de relatos de viagens supostamente realizadas por sábios gregos com o intuito de adquirir conhecimento pelo mundo (Neugebauer 1969, p. 148; confira também Kirk, Raven \& Schofield 1983, p. 76).

Não vejo qualquer necessidade de se preservar -tendo contra sua historicidade uma série de objeções- uma viagem de Tales ao Egito para explicar alguns pontos de contato existentes entre a matemática grega e a egípcia. Ele pode muito bem ter recebido informações sobre a matemática egípcia, como estou bastante seguro em acreditar, da boca de mercadores ou de marinheiros milésios. Era comum na Grécia, às pessoas interessadas em novidades se dirigirem aos portos a fim de ouvir relatos sobre outros lugares, pessoas e culturas. Foi ouvindo os relatos de marinheiros nos portos que os gregos puderam acumular informações suficientes para, por exemplo, elaborar os seus primeiros portulanos.

Percebe-se que, ao mesmo tempo em que rejeito a proposta tão em moda hoje, de que o Egito seria o berço da matemática grega, reconheço que algumas técnicas matemáticas podem ter sido intercambiadas. Repiso que este intercâmbio somente foi possível em face do caráter eminentemente prático apresentado pela matemática grega nesse momento inicial.

\footnotetext{
${ }^{17} \mathrm{~A}$ altura da pirâmide e a $1 / 2$ do lado da base adicionado à sombra da pirâmide são os catetos de um triângulo retângulo isósceles, portanto, os raios de Sol e a sombra da pirâmide devem formar um ângulo de $45^{\circ}$.
} 
Pode-se acreditar que Tales tenha realizado a medição da distância dos navios em alto-mar, mas isso num caráter essencialmente prático. Tales certamente era "um homem de inteligência prática" (Barnes 1979, p. 71), como o descreve muito propriamente Jonathan Barnes. O que podemos sustentar é que Tales conquistou reputação dentre os gregos realizando proezas de medição e algumas obras de engenharia.

Face ao exposto, não acredito que Tales tenha realizado qualquer medição utilizando um conhecimento geométrico adquirido e organizado a priori de forma dedutiva como aquele que lhe foi atribuído por Proclo. ${ }^{18}$ Aceitar o relato de Proclo, isso sim, é abraçar a doutrina do milagre grego ${ }^{19} \mathrm{Um}$ conhecimento desse tipo requer algumas ferramentas lógicas que, pelo que sabemos, não estavam disponíveis a Tales de Mileto. ${ }^{20}$ Seguindo a proposta de A. Szabó, afirmo que somente sob o impacto da filosofia eleática pode ter surgido dentre os gregos a geometria como nos foi apresentada por Euclides nos Elementos. ${ }^{21}$ Destarte, a matemática como conhecemos hoje dependeu da formulação por Parmênides dos princípios que fundamentam a lógica tradicional (Grimberg 2007, p. 60). São eles:

1. princípio da dupla negação;

2. princípio da identidade;

3. princípio de não-contradição.

Acrescenta-se a esses princípios uma das mais poderosas ferramentas de demonstração, o raciocínio por absurdo. Sem esse aparato lógico os gregos não poderiam ter desenvolvido a matemática de forma dedutiva, característica essa que os separou de uma vez por todas dos babilônios e egípcios.

Essa distinção é tão drástica que, somente depois da elaboração e incorporação na matemática grega dos princípios fundamentais da lógica clássica, podemos apontar uma diferença qualitativa entre essa matemática, agora dedutiva, daquela dos egípcios, predominantemente prática. ${ }^{22}$ Essa diferença é tão impor-

${ }^{18}$ São eles (DK 11 A 11):

1. Qualquer diâmetro efetua a bissecção do círculo em que é traçado.

2. Os ângulos da base de um triângulo isósceles são iguais.

3. Ângulos opostos pelo vértice são iguais.

4. Se dois triângulos têm dois ângulos e um lado em cada um deles respectivamente iguais, então esses triângulos são iguais.

${ }^{19}$ Proclo escreveu no século V a. C., mas apoia-se na obra de Eudemo, um discípulo de Aristóteles. Os estudiosos, como informa Barnes, têm se mostrado relutantes em dar crédito às informações de Eudemo (Barnes 1979, p. 75).

${ }^{20}$ Irineu Bicudo descreve em que consiste, hoje em dia, uma teoria matemática: "Ao desenvolver uma teoria, a missão do matemático é definir os conceitos da teoria e demonstrar as propriedades de tais conceitos. Ora, definir um conceito significa explicá-lo em termos de outros conceitos já definidos, e demonstrar uma proposição significa argumentar sobre sua validade, usando as regras de inferência fornecidas pela lógica, a partir de proposições já anteriormente demonstradas" (Bicudo 1998, p. 306).

${ }^{21}$ Boyer aponta também para essa possibilidade. Ele afirma: "Que foram os gregos que acrescentaram à geometria o elemento novo da estrutura lógica é quase universalmente admitido hoje, mas permanece a grande questão de saber se esse passo crucial foi dado por Tales ou por outros mais tarde -talvez dois séculos mais tarde até" (Boyer 1968, pp. 33, 53).

${ }^{22}$ Florian Cajori e outros historiadores da matemática clássicos como Allman e Cantor perceberam corretamente que existe uma diferença qualitativa entre a matemática grega e a egípcia, somente não atentaram 
tante que, após a referida incorporação, podemos perceber facilmente um progresso na matemática grega sem paralelos na história antiga. $\mathrm{O}$ conhecimento matemático dos egípcios, por exemplo, em 1000 anos, permaneceu praticamente o mesmo, enquanto a matemática grega avançou a passos largos em menos de 500 anos. A matemática tornou-se um campo de estudos promissor e bastante eficaz, inclusive prestando-se a diversas aplicações (Mlodinow 2001, p. 15), principalmente na astronomia. Constata-se facilmente o impacto que a estruturação dedutiva deu na matemática examinando as contribuições de matemáticos da envergadura de Euclides, Apolônio e Arquimedes. 
Barnes, J. (1979), The Presocratic Philosophers, London: Routledge \& Kegan Paul. (Versão portuguesa utilizada de Júlio Fischer: Filósofos Pré-Socráticos, São Paulo: Martins Fontes, 2003.)

Bicudo, I. (1998), "Platão e a Matemática", Revista de Letras Clássicas 2: 301-315.

Bongiovanni, V. (2007), "O Teorema de Tales: uma ligação entre o geométrico e o numérico”, REVEMAT - Revista Eletrônica de Educação Matemática 2.5: 94-106.

Boyer, C. B. (1968), A History of Mathematics, New York: John Wiley \& Sons, Inc. (Versão portuguesa utilizada de Elza Gomide: História da matemática, São Paulo: Blücher, 2aㅡ ed., 1996.)

Brun, J. (1968), Les présocratiques, Paris: P.U.F. (Versão portuguesa utilizada de Armindo Rodrigues: Os Pré-Socráticos, Lisboa: Edições 70, 1991.)

Burnet, J. (1892), Early Greek Philosophy, London and Edinburgh: A. and C. Black. (Versão portuguesa utilizada de Vera Ribeiro: A aurora da filosofia grega, Rio de Janeiro: PUCRio/Contraponto, 2006.)

Cajori, F. (1893), A History of Mathematics, London: Macmillan and Co. (Versão portuguesa utilizada de Lázaro Coutinho: Uma história da matemática, Rio de Janeiro: Ciência Moderna, 2007.)

de Andrade Martins, R. (2000), “Arquimedes e a coroa do rei: problemas históricos”, Caderno Catarinense de Ensino de Física 17(2): 115-121.

Diels, H. (1952), Die Fragmente der Vorsokratiker: Griechisch und Deutsch, Herausgegeben von Walther Kranz, Zürich: Weidmann, 3 Bd.

Eves, H. (1958), An Introduction to the History of Mathematics, New York: Rinehart. (Versão portuguesa utilizada de Higyno H. Domingues: Introdução à história da matemática, Campinas: Unicamp, 2004.)

Grimberg, G.É. (2007), "Parmênides e a Matemática”, Anais de Filosofia Clássica 1(1): 55-68.

Guedj, D. (1998), Le Théorème du Perroquet, Paris: Editions du Seuil. (Versão portuguesa utilizada de Eduardo Brandão: O teorema do papagaio, São Paulo: Companhia das Letras, $2^{\underline{a}}$ ed., 2008.)

Havelock, E.A. (1981), The Literate Revolution in Greece and its Cultural Consequences, Princeton, N.J.: Princeton University Press. (Versão portuguesa utilizada de Ordep José Serra: A revolução da escrita na Grécia e suas consequências culturais, São Paulo: Unesp; Rio de Janeiro: Paz e Terra, 1996.)

Kirk, G. S., J. E. Raven, e M. Schofield (1983), The Presocratic Philosophers: A Critical History with a Selection of Texts, Cambridge: Cambridge University Press, 2a ed. (Versão portuguesa utilizada de Carlos Alberto Louro Fonseca: Os filósofos pré-socráticos, Lisboa: Calouste Gulbenkian, 6aㅡ ed., 2008.)

Laêrtios, D. (2008), Vidas e doutrinas dos filósofos ilustres, tradução do grego, introdução e notas de Mário da Gama, Brasília: UnB, 2ae ed.

Mlodinow, L. (2001), Euclid's Window: The Story of Geometry from Parallel Lines to Hyperspace, New York: Free Press. (Versão portuguesa utilizada de Enézio E. de Almeida Filho: A janela de Euclides: a história da geometria, São Paulo: Geração Editorial, 2010.)

Neugebauer, O. (1969), The Exact Sciences in Antiquity, New York: Dover. 
Reale, G. (1975-1980), Storia della filosofia antica in 5 volumi, Milano: Vita e pensiero. (Versão portuguesa utilizada de Marcelo Perine: História da filosofia antiga, São Paulo: Loyola, $3^{3}$ a ed., 1999.)

Vernant, J.P. (1962), Les Origines de la pensée grecque, Paris: CNRS. (Versão portuguesa utilizada de Ísis Borges B. Da Fonseca: As origens do pensamento grego, Rio de Janeiro: Difel, 16 $6^{\mathrm{a}}$ ed., 2006.)

Yates, F.A. (1964), Giordano Bruno and the Hermetic Tradition, London: Routledge \& Kegan Paul. (Versão portuguesa utilizada de Yolanda Steidel de Toledo: Giordano Bruno e a tradição hermética, São Paulo: Cultrix, 1987.) 